\title{
COMPARISON STUDY OF GRINDING AND SLURRY METHOD ON PHYSICOCHEMICAL CHARACTERISTIC OF ACYCLOVIR - SUCCINIC ACID COCRYSTAL
}

\author{
FAUZI RAHMAN ${ }^{1}$, AGNES NUNIEK WINANTARI ${ }^{2}$, SISWANDONO ${ }^{3}$, DWI SETYAWAN ${ }^{1 *}$
}

${ }^{1}$ Department of Pharmaceutics, Faculty of Pharmacy, Airlangga University, Dharmawangsa Dalam - 60286, Indonesia. ${ }^{2}$ Department of Pharmaceutics, Faculty of Pharmacy, Surabaya University, Raya Kalirungkut - 60293, Indonesia. ${ }^{3}$ Department of Chemistry, Faculty of Pharmacy, Airlangga University, Dharmawangsa Dalam - 60286, Indonesia. Email: dwisetyawan-90@ff.unair.ac.id

Received: 28 October 2016, Revised and Accepted: 15 December 2016

ABSTRACT

Objective: This study aimed to compare the characteristics of acyclovir (ACV)-succinic acid (SA) cocrystal with grinding and slurry method.

Methods: Cocrystals were prepared using grinding and slurry methods. Physicochemical characterizations were performed using powder X-ray diffraction (PXRD), differential scanning calorimetry, Fourier transform infrared (IR) spectroscopy, scanning electron microscope (SEM), and dissolution test.

Results: The study revealed that cocrystal of ACV-SA showed a decrease in the melting temperature, i.e., $175.10^{\circ} \mathrm{C}$, respectively, in comparison with the melting point of the constituent materials (ACV $253.53^{\circ} \mathrm{C}$ and SA $187.29^{\circ} \mathrm{C}$ ). PXRD diffractogram showed that cocrystal with grinding method exhibited new diffraction peaks at angle $2 \theta=8.92^{\circ} ; 16.24^{\circ}$; and $17.14^{\circ}$, while PXRD diffractogram of cocrystal with slurry method exhibit new diffraction peaks at angle $2 \theta=16.25^{\circ}$, and $19.63^{\circ}$. Characterization with IR spectroscopy showed the disappearance of transmission peaks at $3441 \mathrm{~cm}$ disappearance of $\mathrm{C}=0$ stretch at $1584 \mathrm{~cm}$ and $1612 \mathrm{~cm}$. Dissolution efficiency of each treatment group calculated the efficiency of dissolution in $15^{\text {th }}$ minutes, grinding method cocrystal with grinding time 15 minutes give the dissolution efficiency were $54.23 \%$. Slurry method cocrystal with solvent concentration $12 \mathrm{ml} / \mathrm{g}$ gives the high value of the dissolution efficiency is 74.36\%. SEM micrographs showed that cocrystals prepared by solvent evaporation method have differences crystal form at magnification 5000× magnification compared to pure ACV and physical mixture.

Conclusion: The study concluded that cocrystals of ACV-SA were successfully formed using grinding and slurry methods. The formed cocrystals of ACV-SA exhibited different physicochemical characteristics as compared to the constituent materials. The formed cocrystals prepared by slurry method have a high intensity of diffraction peak on X-ray diffraction and highest dissolution efficiency at 15 minutes rather than grinding method cocrystal.

Keywords: Cocrystal, Acyclovir, Succinic acid, Grinding, Slurry, Powder X-ray diffraction, Fourier transform infrared, Dissolution rate.

(C) 2017 The Authors. Published by Innovare Academic Sciences Pvt Ltd. This is an open access article under the CC BY license (http://creativecommons. org/licenses/by/4. 0/) DOI: http://dx.doi.org/10.22159/ajpcr.2017.v10i3.15925

\section{INTRODUCTION}

Active pharmaceutical ingredients (API) with low solubility (poor soluble drugs) are the issues on the development of the production of drugs for the pharmaceutical industry. Drugs that are included in the Biopharmaceutics Classification System Class IV is a challenge for the development of pharmaceutical preparations due to their low solubility and low permeability so did the rate of dissolution. Acyclovir (ACV) is a purine nucleoside analog antiviral drug active against herpes simplex virus Types 1 and 2 and Varicella zoster virus, which has a solubility of about $1.62 \mathrm{mg} / \mathrm{ml}$. ACV with low solubility in water, causing low oral bioavailability at around $15-20 \%$ [1]. The active ingredient which has solubility in water under $1 \%(10 \mathrm{mg} / \mathrm{ml})$ in the $\mathrm{pH}$ range $1-7$ at $37^{\circ} \mathrm{C}$ will potentially cause bioabsorption problems. Similarly, if the intrinsic dissolution rate of $<0.1 \mathrm{mg} / \mathrm{cm}^{2}$, the rate of dissolution will limit absorption. The dissolution rate of the API poorly soluble in water can be improved using cocrystal approach. Pharmaceutical cocrystal provides an alternative way to modify the physicochemical properties of APIs, besides salt formation [4].

Cocrystal defined as a crystalline material consisting two or more solid components in a stoichiometric ratio of noncovalently bound, and all the components are in solid form at room temperature [12]. Cocrystal itself is a crystalline solid material modification method for changing the physical properties of the ingredients, especially the solubility properties of the drug. Increasing drug solubility with cocrystal formation due to changes in the strength of the crystal lattice and also increase the affinity of the solvent [11]. Various evaluations of cocrystal prove that the establishment of cocrystal can be a positive influence on some physical properties of medicinal chemistry, among others, solubility, melting point, stability, and bioavailability $[7-9,11]$. Cocrystal can be formed through various methods such as grinding, slurry, evaporation, sublimation, dissolution, and sonication. So far, it has not been reported to influence the manufacturing process preparation of a drug with a grinding method and slurry on the formation of ACVsuccinic acid (SA) cocrystal.

Cocrystals incorporate pharmaceutically acceptable guest molecules, called as coformers, into a crystal lattice along with the API [10]. SA is a coformer with generally regarded as safe status with a pKa: 4.21 . Kind of bonding that occurs between ACV and SA are heterosinthon occurs between the $\mathrm{OH}$ group contained in the SA interacts with purine group contained in the ACV and there is also a bond between $\mathrm{OH}$ group contained in the SA interacts with double bond of O on ACV so that the bond they form strong hydrogen bridge forming supramolecular assemblies cocrystal or networking may increase the release of ACV molecules to dissolve in water formed by hydrogen bonds or intermolecular interaction crystal mixture, following physicochemical character of SA. SA as coformer has been investigated through the establishment of fluoxetine HCl-SA cocrystal. The cocrystal showed increased solubility 2 times greater than the API.

The mechanochemical method through grinding without additional solvent (neat grinding), as well as a small amount of liquid which 
is added to the grinding process (liquid assisted grinding/LAG), is a method of forming cocrystal become more efficient than the solvent method [11]. The addition of a solvent in the LAG method can significantly increase the formation of cocrystal. The use of cocrystal formation through LAG method had been done using a drug model conformer caffeine and citric acid.

The slurry method is a method that can be used as an alternative of making cocrystal. In this method, a muddy/suspension is formed by adding a small amount of solvent to the physical mixture (PM) of API and the conformer.

API-conformer suspension in a solvent and then stirring until the formation process is completed cocrystal. The solvent is added to a mixture of drug-conformer to mediate the transformation of solid reactants to form cocrystal. On the formation sonic slurry cocrystal method, namely the establishment of cocrystal using a slurry method with the aid of sonication, it is known that the concentration of the solvent added has a major role in the rate of formation of cocrystal. Cocrystal can be formed when the ingredients and conformer together in a phase of saturation in the solvent used [2]. Physicochemical characterization was performed by powder X-ray diffraction (PXRD), Fourier transform infrared spectroscopy (FTIR), dissolution test, and scanning electron microscope (SEM).

Based on this background, this study is to compare physicochemical characteristics of ACV-SA cocrystal made by grinding and slurry method compared to solvent evaporation (SE) method cocrystal which is the most common method used in the formation of cocrystal.

\section{MATERIALS AND METHODS}

Materials ACV was purchased from Sigma-Aldrich ${ }^{\circledR}$, China. SA was purchased from Emsure ${ }^{\circledR}$, Germany. Ethanol was purchased from Emsure $^{\circledR}$, Germany.

\section{Methods}

Thermal analysis using differential scanning calorimetry (DSC)

Sample weighed $5 \mathrm{mg}$ then inserted into sample aluminum pan and inserted into the DSC instrument. Tool set with heating rate $10^{\circ} \mathrm{C} / \mathrm{min}$ in the heating temperature range $30-300^{\circ} \mathrm{C}$. The melting point of the sample was observed through a thermogram generated profiles. The analysis was performed by overlaying thermogram between ACV, SA, PM of ACV-SA and ACV-SA cocrystal. Cocrystal formation indicated the formation of a new solid phase at thermogram with different melting points of the two constituent materials is ACV and SA $[1,5]$.

\section{Preparation of phase diagram of binary system}

Each of the components weighed and made PM with ratio of ACV-SA respectively as follows: $(0: 10),(1: 9),(2: 8),(3: 7),(4: 6),(5: 5),(6: 4)$, (7:3), (8:2), (9:1), (10:0). The melting point of PMs was determined by DSC thermal analysis. Phase diagrams of binary systems between two components were made by plotting the melting point (endothermic peak) obtained from DSC thermal analysis with the composition of each binary mixture of ACV-SA. Based on the data from the binary system could be determined which form compounds molar ratio cocrystal.

\section{Preparation of ACV-succinic an acid PM}

ACV and SA (equimolar) carefully weighed; 500 and $262.19 \mathrm{mg}$, respectively. Both powders were homogeneously mixed in a mortar.

\section{Preparation of cocrystal using SE method}

The PM of ACV-SA dissolved in ethanol. The two solutions then mixed and stirred until homogeneous. Mixture solution obtained subsequently evaporated at room temperature for $48 \mathrm{hrs}$. Cocrystal then stored in a desiccator.

\section{Preparation of cocrystal using grinding method (Grinding)}

Making cocrystal with grinding method was done by creating a PM of ACV-SA at a molar ratio of 1:1 (656.0 mg ACV and $344.0 \mathrm{mg}$ of SA) of 5 pieces. Each mixture then ground manually using a mortar and a stamper on a wide variety of grinding time $(5,10,15,20$, and 30 minutes). Each cocrystal then analyzed using PXRD, FTIR and determined the dissolution rate profile.

\section{Preparation of cocrystal using slurry method (Slurry)}

Making cocrystal using slurry method was done by creating a PM of ACV-SA at a molar ratio of 1:1 (656.0 mg ACV and $344.0 \mathrm{mg}$ of SA) of 5 pieces. Ethanol added in the mixture which expressed by $\mu$, i.e., in $\mathrm{ml}$ solvent volume that was divided by the sample weight (mg).

Each PM of ACV-SA was added by ethanol in the variation of $\mu$ was at 6 , $8,10,12,14 \mathrm{ml} / \mathrm{mg}$. The mixture suspension then stirred in the beaker glass with a stirrer magnetic which stirred for 5 minutes, and then the solvent allowed evaporating at room temperature. Cocrystal formed then it was analyzed using PXRD, FTIR and determine the dissolution rate profile.

\section{Characterization by PXRD}

The crystal structure was analyzed by PXRD in the following conditions: Target/filter (monochromator) Cu, voltage $40 \mathrm{kV}, 30 \mathrm{~mA}$ current, slit width of 0.2 inches. The data were collected by scanning mode $0.2-0.5^{\circ}$ per minute and scanning distance $2 \theta=5-40^{\circ}$. The analysis was conducted by overlaying the diffractogram of the ACV, SA, PM of ACV-SA and ACVSA cocrystal. The new formation of solid crystalline or cocrystal could be seen by the formation of the different profile of diffractogram than ACV and SA diffractogram [5,13].

\section{Characterization using FTIR spectroscopy}

Samples mixed by using $\mathrm{KBr}$ crystal in the ratio of sample: $\mathrm{KBr}(1: 100)$ and ground until homogeneous then compressed at 20 psi using $\mathrm{KBr}$ plate compressor. The spectra were measured using FTIR spectroscopy Jasco-4200. Then, the disc was placed in the sample holder and recorded. Samples were observed in the absorption band or wave number $4000-625 \mathrm{~cm}^{-1}$. The analysis was performed by comparing the IR spectra of cocrystal with IR spectra of ACV and SA. Cocrystal was formed when there was a change in the absorption frequency of specific functional groups on the pure substance. The change indicated the interaction between ACV with SA through a particular functional group [1].

\section{Determining dissolution rate}

Determination of dissolution rate conducted on three groups of samples. All of which were pure ACV, PM of ACV-SA and ACV-SA cocrystal. Each sample weighed the equivalent of $100 \mathrm{mg}$ of ACV. The dissolution test performed as follows: Dissolution profile determined by using USP II method (paddle-type instrument), phosphate buffer as dissolution medium at pH 6.8 as much as $900 \mathrm{ml}$, stirring speed at $50 \mathrm{rpm}$, and temperature was $37 \pm 0.5^{\circ} \mathrm{C}$. After the dissolution media temperature reached $37 \pm 0.5^{\circ} \mathrm{C}$ samples that have been prepared to be inserted into the dissolution vessel and stirrer rotated at $50 \mathrm{rpm}$. Sample solution was taken at intervals time of 5, 10, 15, 20, 30 and 45 minutes as much as $5.0 \mathrm{ml}$, and then filtered with filter paper $0.45 \mu \mathrm{m}$. In each sample collection replacement dissolution medium volume number of samples was $5.0 \mathrm{ml}$ with the same temperature. Furthermore, $1.0 \mathrm{ml}$ aliquot was inserted in $10.0 \mathrm{ml}$ volumetric flask and phosphate buffer was added to the appropriate mark.

\section{Characterization using SEM}

Sample was placed on the sample holder aluminum and coated with platinum (Pt) to a thickness of $10 \mathrm{~nm}$. Then, these samples would be observed on various magnification SEM tool. Voltage was to be set at $20 \mathrm{kV}$ and $12 \mathrm{~mA}$ current. The analysis was performed by comparing the morphology of cocrystal and morphology of ACV and SA. Cocrystal 
form showed their new crystal morphology that was different from ACV and SA [1].

\section{RESULTS AND DISCUSSION}

Phase diagram of binary system

A phase diagram of ACV-SA was made by plotting the melting point (endothermic peak) obtained from analysis by DSC PM of ACV-SA molar ratio (0:10), (1:9), (2: 8), (3:7), (4:6), (5:5), (6:4), (7:3), (8:2), (9:1) and $(10: 0)$. The result of a phase diagram of binary system which occurred from the physical interaction between ASK-AS showed the type of a phase congruent diagram (cocrystal). It has two eutectics melting point $\left(E_{1}\right.$ and $\left.E_{2}\right)$, the first eutectic point $\left(E_{1}\right)$ at a ratio $(2: 8)(b / b)$ in a temperature of $166.37^{\circ} \mathrm{C}$ and the second eutectic one $\left(\mathrm{E}_{2}\right)$ at a ratio (9:1) in a temperature of $163.37^{\circ} \mathrm{C}$. ACV melting point decreased as much $253.53^{\circ} \mathrm{C}$ in adding of $\mathrm{SA}$ and reached a minimum value at the first eutectic point $\left(E_{1}\right)$. From the first eutectic point $\left(E_{1}\right)$, the melting point increased due to an addition of SA which would cause the mixture of melting point increased and reached a maximum temperature at $176.23^{\circ} \mathrm{C}$. There is an equilibrium phase of liquid and solid in this point. This maximum temperature is a congruent melting point of compound molecule. Increasing number of $\mathrm{ACV}(\mathrm{b} / \mathrm{b})$ which occurred continuously would cause the decreasing melting point of binary mixture in minimum temperature of succinate acid which called as the second eutectic point $\left(E_{2}\right)$. Based on the result on binary diagram phase, it showed that a cocrystal was formed at a ratio 1:1 and a melting point of cocrystal was around $176.23^{\circ} \mathrm{C}$. From the phase diagram, it can be concluded that compound molecule in binary system of ASK-AS with a solid condition was in an equilibrium phase with the same composition as liquid phase. Binary phase diagram was obtained from the DSC analysis which the formation cocrystal on PM molar ratio (1:1) with melting point of about $156.42-173.58^{\circ} \mathrm{C}$ (Fig. 1).

DSC

Thermal analysis by DSC performed at temperature range of $30-300^{\circ} \mathrm{C}$ with a heating rate $5^{\circ} \mathrm{C} / \mathrm{min}$. Thermogram comparison of ACV, SA, PM of ACV-SA (1:1), SE ACV-SA cocrystal (1:1) (Fig. 2). DSC thermogram data from the melting point of ACV-SA cocrystal: $175.10^{\circ} \mathrm{C} \triangle \mathrm{H}$ : $-1.86 \mathrm{~J} / \mathrm{g}$, melting point of PM ACV-SA: $164.72^{\circ} \mathrm{C} \Delta \mathrm{H}:-3.89 \mathrm{~J} / \mathrm{g}$. The melting point indicated resources decreased interactions between materials.

ACV DSC profile indicated that there was endothermic peak at the temperature $253.53^{\circ} \mathrm{C}$. The results of melting point ACV used were in conformity with the existing literature that is $254.4^{\circ} \mathrm{C}(\mathrm{COA}, 2012)$. ASK and AS PMs equimolar with (1:1) comparison showed endothermic peak at $164.72^{\circ} \mathrm{C}$. ASK-AS cocrystal SE method with molar comparison (1:1) showed endothermic peak at $175.10^{\circ} \mathrm{C}$ and it is a maximum temperature in solid and liquid phase equilibrium. This maximum temperature is a congruent melting point molecular compounds. The results of the research on thermal analysis with a decrease in the melting point of cocrystal with (1:1) comparison, SE method compared with pure components and PMs, indicated that cocrystal is formed.

\section{PXRD}

Characterization of ACV-SA that is grinding cocrystal was done with the analysis conducted at PXRD diffractometer interval with angle $2 \theta=5.0-50.0^{\circ}$. Comparison of diffractogram ACV-SA cocrystal with variations of grinding time was $5,10,15,20$ and 30 minutes. Based on Fig. 3 ratio of PXRD diffractogram, there was a new diffraction peak at grinding cocrystal when compared to SE ACV-SA cocrystal. In SE ACV-SA cocrystal, there were 3 new peaks at $2 \theta=11.2^{\circ} ; 13.66^{\circ} ; 16.2^{\circ}$. In ACV-SA grinding cocrystal with grinding time 15 minutes provide peak at most that 3 new peak at $2 \theta=8.92^{\circ} ; 16.24^{\circ}$ and $17.14^{\circ}$.

The characterization of cocrystal was analyzed using PXRD in terms to see whether there is a new peak of $2 \theta\left({ }^{\circ}\right)$ or not when it compared to diffractogram profile from each materials used. The comparison of cocrystal diffractogram profile was (1:1). The SE method is used by

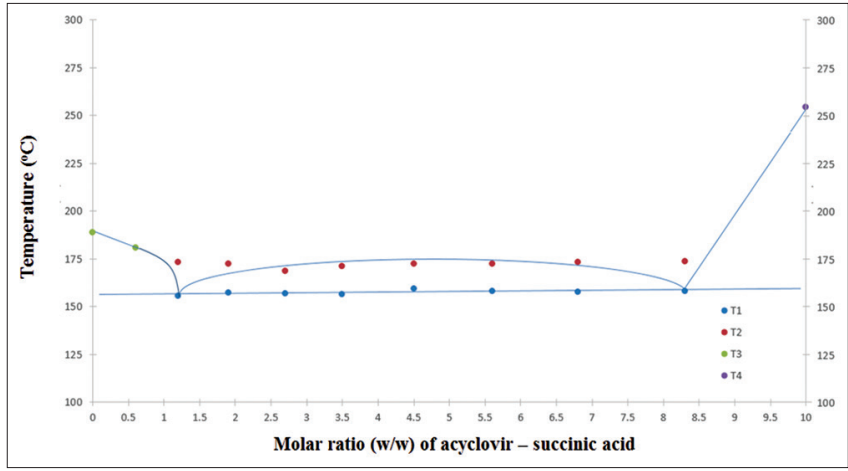

Fig. 1: A phase diagram of a binary system of acyclovir-succinic acid with different molar ratio fraction

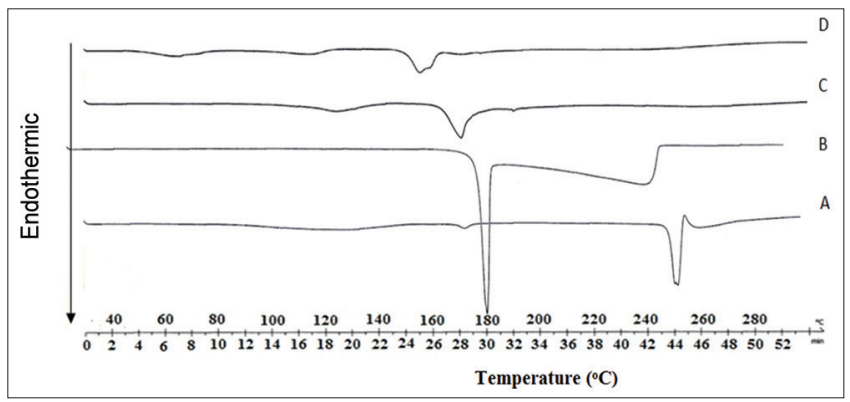

Fig. 2: Thermogram comparison of acyclovir (ACV) (a), succinic acid (SA) (b), physical mixture ACV-SA (1:1) (c), solvent evaporation ACV-SA cocrystal (d)

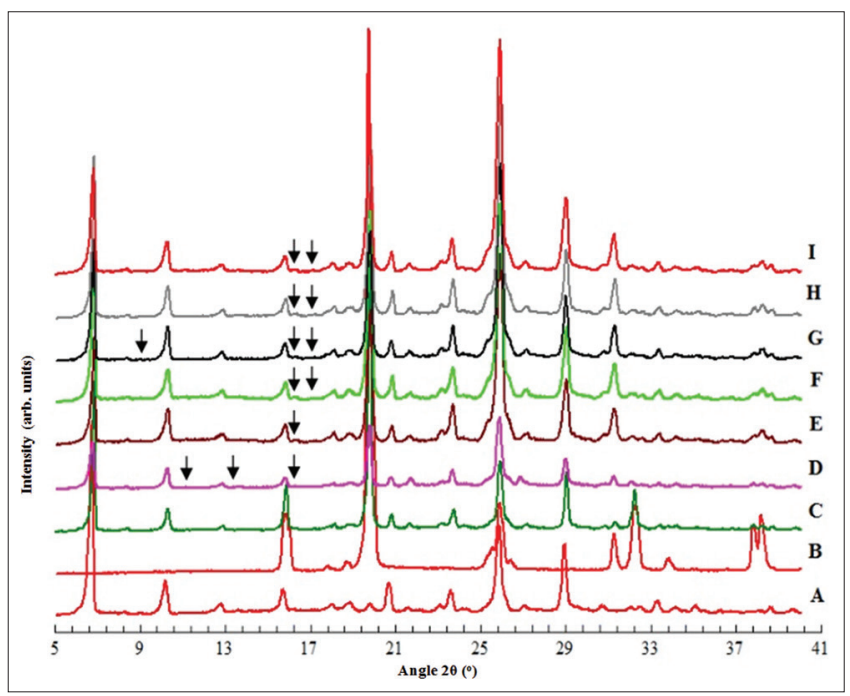

Fig. 3: Powder X-ray diffraction diffractogram comparison of acyclovir (ACV) (a), succinic acid (SA) (b), physical mixture ACV-SA 1:1 (c), solvent evaporation (SE) ACV-SA cocrystal (d), grinding ACV-SA 5 minutes (e), 10 minutes (f), 15 minutes (g) 20 minutes (h), 30 minutes (i). Arrows ( $\downarrow$ ) indicates the specific diffraction peaks of cocrystal obtained from SE and grinding method

ethanol solvent showed that there are three new peaks which can be seen at $2 \theta\left(^{\circ}\right) 11.20^{\circ}, 13.66^{\circ}$, and $16.20^{\circ}$ with intensity quantities of each peak $2 \theta\left({ }^{\circ}\right)$ as follows 850,66 , and $47 \mathrm{cps}$. The result of using SE method showed that cocrystal has been formed. It used a diffractogram of PXRD with some new peaks at $2 \theta\left({ }^{\circ}\right)$ in the profile of cocrystal diffractogram at a ratio (1:1). 
In this case, new peak cocrystal diffraction in grinding method with the duration time for about 5 minutes would create a new diffraction peak. There are 2 new diffraction peaks in cocrystal grinding method at grinding duration for 10 minutes, 3 new diffraction peaks in cocrystal grinding method for 15 minutes, 2 new diffraction peaks in cocrystal grinding method for around 20 minutes. There are two new diffraction peaks in the grinding method of cocrystal with time duration 30 minutes, from the fifth grinding method of cocrystal, ASKAS cocrystal has been chosen with grinding time 15 minutes because it is the most new diffraction peaks which provide with high intensity; therefore, it can be concluded that ASK-US cocrystal with duration of time 15 minutes was cocrystal with optimal treatment.

It indicated that grinding method occurred shifting distance between its crystal lattice in forming cocrystal. Shifting the crystal lattice due to the influence of mechanical activation provided when grinding, resulting in a variety of deformation and damage to a solid (Fig. 4). If the energy supplied is large enough, the three-dimensional crystals will be damaged [13].

Diffractogram comparison of ACV-SA slurry cocrystal with amount variation of solvent concentration is added, which is $6,8,10,12$ and $14 \mathrm{ml} / \mathrm{g}$. There is a new diffraction peak only in slurry cocrystal when it compared with SE ACV-SA cocrystal, seen that slurry method cocrystal with solvent concentration of $6 \mathrm{ml} / \mathrm{g}$ provides new peak at angle $2 \theta=10.8^{\circ}$ and $19.5^{\circ}$ while the solvent concentration of $12 \mathrm{ml} / \mathrm{g}$ provides the new diffraction peaks at an angle $2 \theta=16.2^{\circ}$ and $19.6^{\circ}$ and provide intensity steeper.

There are two new diffraction peaks with a concentration of solvent $6 \mathrm{ml} / \mathrm{g}$, three new diffraction peaks with a concentration of solvent $8 \mathrm{ml} / \mathrm{g}$, a new diffraction peak with a concentration of solvent $10 \mathrm{ml} / \mathrm{g}$, two new diffraction peaks with a concentration of solvent $12 \mathrm{ml}$, and two new diffraction peaks with a concentration of solvent $14 \mathrm{ml} /$ gat cocrystal slurry method. From diffractogram resulted cocrystal ACV-SA slurry method can be concluded that ASKAS cocrystal with concentration of solvent, respectively, 6 and $12 \mathrm{ml} / \mathrm{g}$ constitute an optimal condition at forming cocrystal because it gave high intensity.

This suggests that the formation slurry method of cocrystal as evidenced by a shift in its crystal lattice in line with the rising amount of crystallinity or the number of cocrystal which generated. Increasing the number of slurry cocrystal method due to ethanol solvent which helps accelerate the activation of the interaction between molecules of ACV and SA that will be formed hydrogen bridge quickly and consequently the formation of hydrogen resulted to the formed cocrystal number increased.

\section{FTIR spectroscopy}

The analysis with IR spectroscopy was done by the wave number range $4000-450 \mathrm{~cm}^{-1}$. The comparison of IR spectra of SE ACV-SA cocrystal and the grinding ACV-SA cocrystal with the solvent concentration of 6 , 8, 10, 12 and $14 \mathrm{ml} / \mathrm{g}$. (Fig. 6).

The result of characterization with IR spectrophotometer, ASK-AS cocrystal with (1:1) comparison, SE method using ethanol solvent presents a new absorption peak that does not show up in the PM and pure components.

IR spectroscopy analysis was done by the wave number range $4000-450 \mathrm{~cm}^{-1}$. The comparison of IR spectra SE ACV-SA cocrystal and slurry ACV-SA cocrystal with the solvent concentration of 6, 8, 10, 12 and $14 \mathrm{ml} / \mathrm{g}$ (Fig. 6).

The shifting value of wave number of the functional cluster in the IR spectrum indicated that the hydrogen bonds interaction between medicinal substances with conformers that formed cocrystal [6]. Related to the making of the ACV-tartaric acid cocrystal, there is also a shifting wave number on a typical cluster that indicates the formation

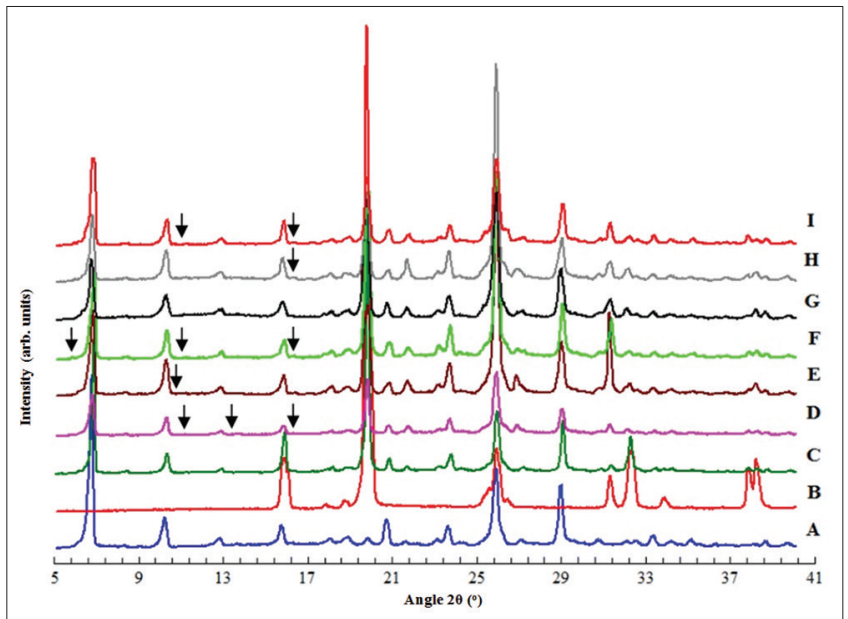

Fig. 4: Powder X-ray diffraction diffractogram comparison of acyclovir (ACV) (a), succinic acid (SA) (b), physical mixture of ACV-SA 1:1 (c), solvent evaporation (SE) ACV-SA (d), slurry ACV-SA $6 \mathrm{ml} / \mathrm{g} \mathrm{(e),} 8 \mathrm{ml} / \mathrm{g}$ (f), $10 \mathrm{ml} / \mathrm{g} \mathrm{(g),} 12 \mathrm{ml} / \mathrm{g} \mathrm{(h),} 14 \mathrm{ml} / \mathrm{g}$ (i), arrows $(\downarrow)$ indicate the specific diffraction peaks of cocrystal obtained from SE method and slurry method

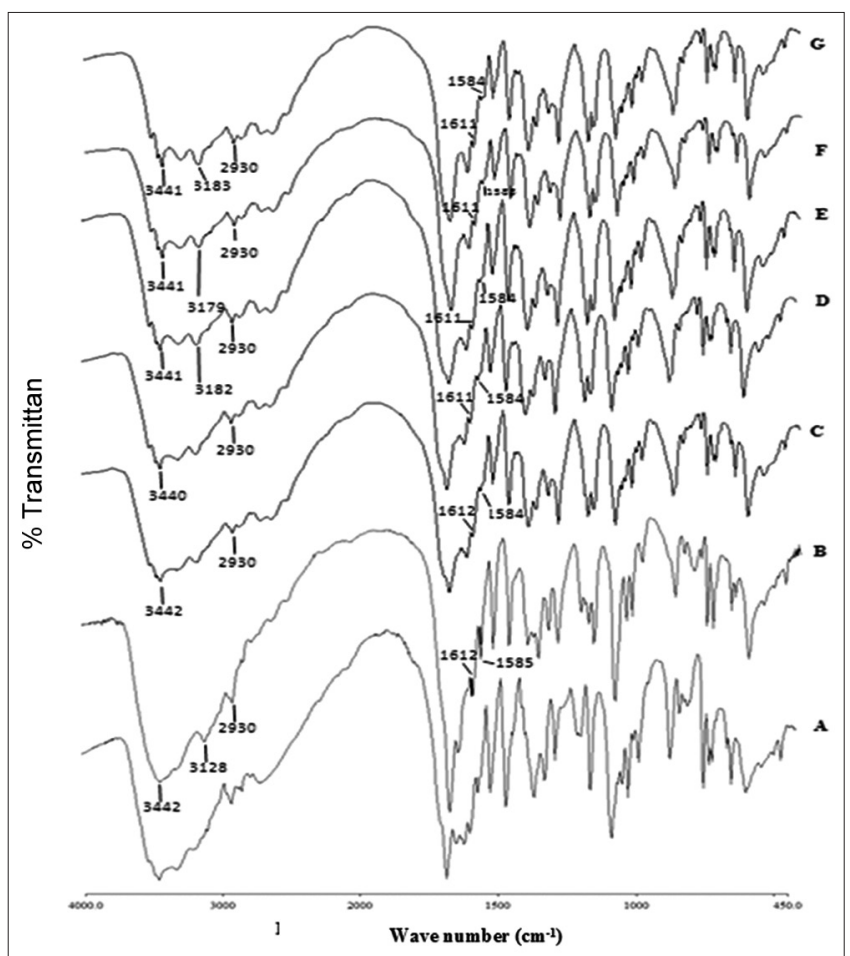

Fig. 5: Infrared spectra of acyclovir (ACV) (a), solvent evaporation ACV-succinic acid (SA) (b), grinding ACV-SA 5 minutes (c), 10 minutes (d), 15 minutes (e), 20 minutes (f) and 30 minutes (g)

of hydrogen bonds between the active ingredient with the conformers itself [6].

Determination of dissolution rate

The results of the determination of dissolution rate of ACV, PM ACV-SA (1:1), SE ACV-SA, grinding ACV-SA 5, 10, 15, 20 and 30 minutes can be seen in Fig. 7.

Dissolution efficiency of each treatment groups was calculated by the dissolution efficiency in $15^{\text {th }}$ minute, grinding cocrystal with the grinding time 15 minutes gives dissolution efficiency is $54.23 \%$. 
The results of dissolution rate of ACV, PM of ACV-SA (1:1), SE ACV-SA, slurry ACV-SA cocrystal with solvent concentration 6, 8, 10, 12 and $14 \mathrm{ml} / \mathrm{g}$ can be seen in Fig. 8.

Slurry ACV-SA cocrystal with solvent concentration $12 \mathrm{ml} / \mathrm{g}$ gives the high value of the dissolution efficiency is $74.36 \%$. It can be concluded that slurry ACV-SA cocrystal by the solvent concentration $12 \mathrm{ml} / \mathrm{g}$ as the optimal conditions in the manufacturing cocrystal.

\section{SEM}

The result of the crystalline form of ACV, SA, PM of ACV-SA (1:1), SE ACV-SA cocrystal by microscopy magnification of $\times 5000$ (Fig. 9). Examination with SEM analysis of SE ACV-SA cocrystal has been formed and it can be seen differences in crystal form at magnification $5000 \mathrm{X}$ compared to ACV and PM.

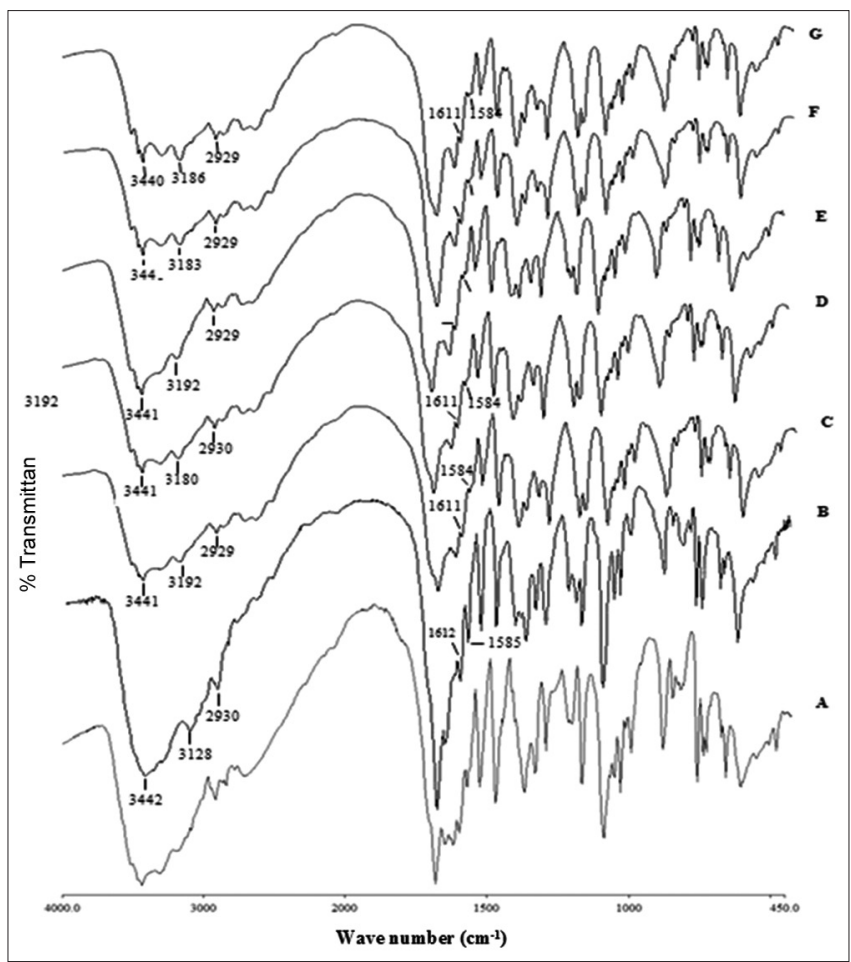

Fig. 6: Infrared spectra of acyclovir (ACV) (a), solvent evaporation ACV-succinic acid (SA) (b), slurry ACV-SA 6 ml/g (c), 8 ml/g (d), $10 \mathrm{ml} / \mathrm{g}(\mathrm{e}), 12 \mathrm{ml} / \mathrm{g}(\mathrm{f})$, and $14 \mathrm{ml} / \mathrm{g}(\mathrm{g})$

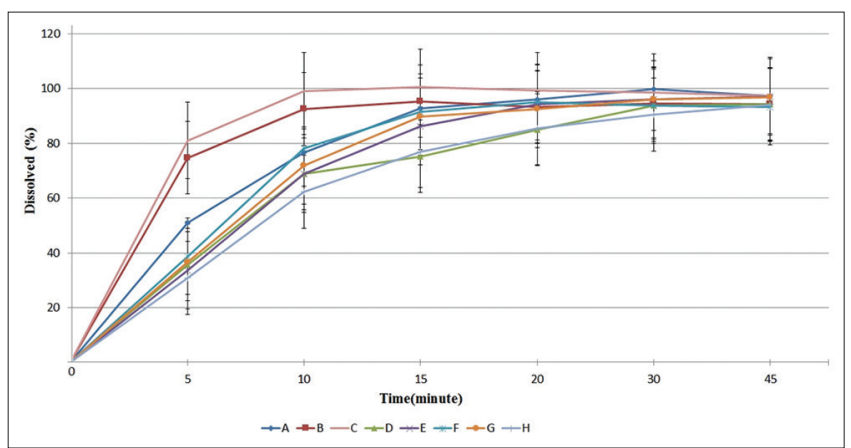

Fig. 7: Profile of dissolution rate acyclovir (ACV) (a), physical mixture ACV-succinic acid (SA) (b), solvent evaporation ACVSA (c), grinding ASK-SA 5 minutes (d), 10 minutes (e), 15 minutes (f), 20 minutes (g), 30 minutes (h) in phosphate buffer of pH 6.8 at $37 \pm 0.5^{\circ} \mathrm{C}$ at $50 \mathrm{rpm}$

\section{CONCLUSION}

Based on the research that has been done, it can be concluded that the difference of time in the grinding method toward the formation of ACV-SA cocrystal causes the difference in the angle of the diffraction peak in PXRD analysis, a shift wave number in the IR spectra and the increasing of the dissolution efficiency in $15^{\text {th }}$ minute.

The difference in solvent concentration in slurry method on the formation of ACV-SA cocrystal causes the difference in the angle of diffraction peak in PXRD analysis, a shift wave number in the IR spectra and the increasing of the dissolution efficiency $15^{\text {th }}$ minute.

The different methods of cocrystal formation of ACV-SA, slurry method cocrystal provide the increasing of the dissolution efficiency in the $15^{\text {th }}$ minute which is larger when it compared with grinding ACV-SA cocrystal formation.

Based on the result, it can be concluded that there is a distinction between ACV, PM of ACV-SA, ACV-SA cocrystal grinding method with variations in grinding time and ACV-SA slurry method cocrystal with variety of solvents $(\mathrm{ml} / \mathrm{g})$.

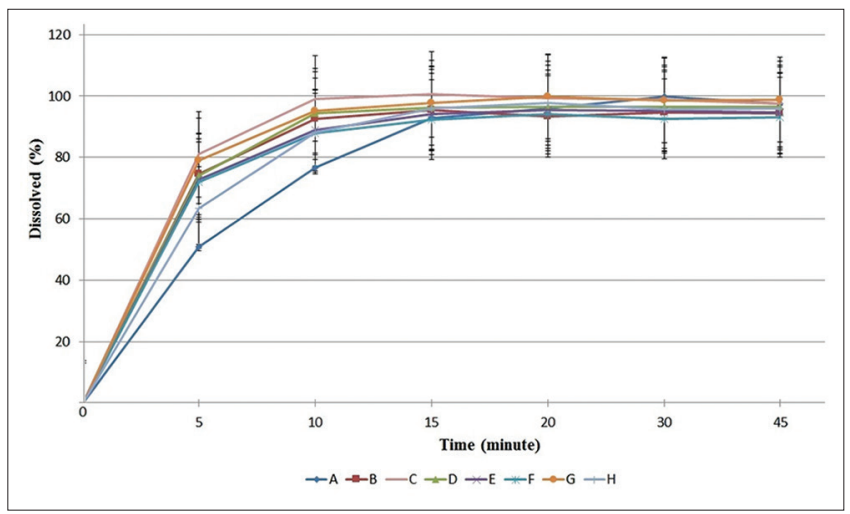

Fig. 8: Profile of dissolution rate acyclovir (ACV) (a), physical mixture ACV-succinic acid (SA) (b), solvent evaporation ACV-SA (c), slurry ASK-SA $6 \mathrm{ml} / \mathrm{g}$ (d), $8 \mathrm{ml} / \mathrm{g}(\mathrm{e}), 10 \mathrm{ml} / \mathrm{g}$ (f), $12 \mathrm{ml} / \mathrm{g}(\mathrm{g}), 14 \mathrm{ml} / \mathrm{g} \mathrm{(h)}$ in phosphate buffer of $\mathrm{pH} 6.8$ at $37 \pm 0.5^{\circ} \mathrm{C}$ at $50 \mathrm{rpm}$

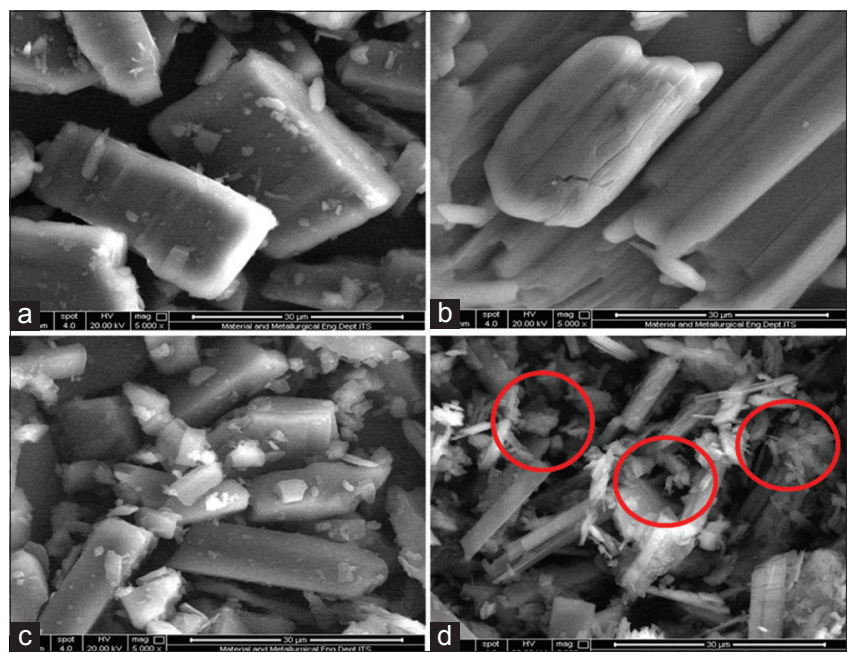

Fig. 9: Examination by microscopy magnification of $\times 5000$ for acyclovir (ACV) (a), succinic acid (SA) (b), physical mixture ACV-SA (1:1) (c), solvent evaporation ACV-SA cocrystal (d) 
This is because the grinding method involves adding a less than optimal energy in forming cocrystal when compared to the other two cocrystal methods such as SE method and the slurry method. While in the slurry method the solvent work as a medium that can help speed up the activation of the interaction between ACV-SA molecules to form hydrogen bridge that when exposed to dissolution medium, the slurry method cocrystal will easily dissolved in advance in the dissolution medium as compared with the grinding method using heat energy generated from mechanical pressure without using a solvent aid [13]. It can be concluded that the forming of ACV-SA cocrystal is more influenced by the solvent used and the solubility of cocrystal components in a solvent which is used when compared to mechanical factors given by grinding method.

\section{ACKNOWLEDGMENT}

The authors would like to thank for the advisors were given suggestion and support to finish this paper.

\section{REFERENCES}

1. Bruni G, Maietta M, Maggi L, Mustarelli P, Ferrara C, Berbenni V, et al. Preparation and physicochemical characterization of acyclovir cocrystals with improved dissolution properties. J Pharm Sci 2013;102:4079-86

2. Friscic T, Jones W. Application of mechanochemistry in the synthesis and discovery of new pharmaceutical forms: Co-crystals, salts, and coordination compounds. In: Wouters J, Quere L, editors. Pharmaceutical Salts and Co-Crystals. Cambridge: The Royal Society of Chemistry; 2012.
3. He G, Jacob C, Guo L, Chow PS, Tan RB. Screening for cocrystallization tendency: The role of intermolecular interactions. J Phys Chem B 2008;112:9890-5.

4. Hiendrawan S, Hartanti AW, Veriansyah B, Widjojokusumo E, Tjandrawinata RR. Solubility enhancement of ketoconazole via salt and cocrystal formation. Int J Pharm Pharm Sci 2015;7(7):160-4.

5. Kern A. Profile analysis. In: Clearfield A, Reibenspies J, Bhuvanesh N, editors. Principles and Applications of Powder Diffraction. Chichester: Blackwell Publishing; 2008.

6. Masuda T, Yoshihashi Y, Yonemochi E, Fujii K, Uekusa H, Terada K. Cocrystallization and amorphization induced by drug-excipient interaction improves the physical properties of acyclovir. Int J Pharm 2012;422(1-2):160-9.

7. Gilmore CJ. X-ray diffraction. In: Storey RA, Ymen I, editors. Solid State Characterization of Pharmaceuticals. Chichester: Blackwell Publishing; 2011.

8. Saunders M, Gabbott P. Thermal analysis-conventional techniques. In: Storey RA, Ymen I, editors. Solid State Characterization of Pharmaceuticals. Chichester: Blackwell Publishing; 2011.

9. Schultheiss N, Newman A. Pharmaceutical cocrystals and their physicochemical properties. Cryst Growth Des 2009;9:2950-67.

10. Shah K, Borhade S, Londhe V. Utilization of co-crystallization for solubility enhancement of a poorly soluble antiretroviral drug ritonavir. Int J Pharm Pharm Sci 2014;6(2):556-8.

11. Sweetman SC, editor. Martindale: The Complete Drug Reference. $36^{\text {th }}$ ed. London: Pharmaceutical Press Publishing; 2009.

12. Thakuria R, Delori A, Jones W, Lipert MP, Roy L, RodríguezHornedo N. Pharmaceutical cocrystals and poorly soluble drugs. Int J Pharm 2013;453:101-25.

13. Zaini E, Halim A, Soewandhi SN, Setyawan D. Increasing the dissolution rate of trimetroprim through cocrystalization method with nicotinamide. Indones Pharm J 2011;5(4):205-12. 